\title{
Autopsy findings in Fatal neck Compression cases at Western Regional Hospital, Pokhara, Nepal
}

\section{Madan Prasad Baral}

Department of Forensic Medicine, Pokhara Academy of Health Sciences, Western Regional Hospital, Pokhara.

\section{Correspondence:}

Dr. Madan Prasad Baral, MD,

MBBS, MD Forensic Medicine

Pokhara Academy of Health Sciences

Western Regional Hospital

Pokhara, Nepal

Email: madanprasadbaral@gmail.com.

Article received : $23^{\text {rd }}$ July 2018

Article accepted : $10^{\text {th }}$ Dec. 2018

\section{ABSTRACT}

Background: Violent asphyxial deaths chiefly include death due to hanging, strangulation, suffocation and drowning. Deaths resulting from hanging and ligature strangulation both show similar type of findings in which the ligature marks at the neck is very important characteristic finding. That's why it is a challenge for forensic experts and needs thorough knowledge and experience to differentiate between them. Some of the typical autopsy findings help autopsy surgeon in such dilemma. Objective of Present study is about the external and internal autopsy findings in fatal neck compression cases specially focusing on hanging and ligature strangulation cases to differentiate and clear the dilemma in such cases. Materials and Methods: Current study was conducted among 103 corpses with compression of neck by ligature materials brought for autopsy examination at Mortuary of Forensic Medicine Department of Western Regional Hospital Pokhara from February2017 to January 2018.Conclusion: In fatal neck compression cases external autopsy findings like dribbling of saliva from angle of mouth, facial pallor, urine and fecal material discharge were common finding in 99 cases of hanging where as it was variable in ligature strangulation cases. Similarly fracture of hyoid bone and thyroid cartilage was found in hanging cases with age greater than 38 years but not in any ligature strangulation cases as an internal autopsy finding.

Key Words: Hanging, Ligature strangulation, Hyoid Bone, Thyroid Cartilage, Neck compression
INTRODUCTION:

Violent deaths includes death due to hanging, strangulation, suffocation and drowning ${ }^{1}$.Mechanical asphyxia is a broad term in which enough external pressure is applied to neck, chest or other areas of body, or the body is positioned in such a way that respiration is difficult or impossible ${ }^{2}$. Asphyxia is defined as lack of oxygen in blood and tissue due toimpaired or absence of exchange of oxygen and carbondioxide on a ventilator basis, leading to death ${ }^{3}$.Death due to asphyxia are caused by failure of cells to receive or utilize oxygen ${ }^{1}$.Violent death is one of unnatural death amongst which hanging and ligature strangulation are common in autopsy examination. Hanging is defined as complete or partial suspension of the body by a ligature tied around the neck and force of the constriction on the neck being applied 
by the weight of the body hanged ${ }^{4}$.Strangulation is a form of violent asphyxia caused by constriction of neck by some means, the force of constriction being other than victim's body ${ }^{5}$.Deaths which were resulting from hanging and ligature strangulation both show similar features in which the ligature marks at the neck is very important characteristic finding in external examination. Though characteristic finding, the ligature mark, found around the neck in both hanging and strangulation creates suspicion in many cases. It is easy to analyze hanging and ligature strangulation when there are presences of some classical features. However all features are infrequently present together. The appliance of pressure on the neck frequently results in findings, which are quite inconsistent. A correct evaluation of various post-mortem findings is necessary in such conditions. Excluding the typical ligature mark, atypical ligature marks are also seen leading to lot of prying in the mind of autopsy surgeon during Autopsy. That's why it is a challenge for forensic experts and needs thorough knowledge and experience to differentiate between them. Some of the typical autopsy findings help autopsy surgeon in such dilemma. Although there are various studies conducted in some countries regarding fatal neck compression cases but quality literature is not available in Nepalese context. That's why author conducted this study with objectives to describe external and internal autopsy findings of fatal neck compression cases of hanging and ligature strangulation.

\section{MATERIALS AND METHODS:}

This is a cross-sectional observational study which was conducted in Department of Forensic Medicine, Western regional Hospital Pokhara. A total of 103 cases of compressed neck by ligature due to hanging and strangulation were included. Total 400 cases were brought for autopsy examination during period of one year from February 2017 to January 2018 and 103 cases of hanging and strangulation were selected for present study. Thorough information about the crime scene investigation findings and photographs were collected from the relevant papers produced by the related police office and studied before conducting post mortem examination. Besides this information collected, both external and internal autopsy findings were observed very carefully with standard national autopsy protocol (uniform guidelines all over country). The findings of autopsy were recorded and analysis was done between various findings of hanging and ligature strangulation.

Inclusion criteria: Fatal neck compression cases due to hanging and ligature strangulation were included in the study.

Exclusion criteria: Decomposed bodies even and undetermined causes of death were excluded.

\section{RESULT:}

In the present study, Total cases of fatal neck compression were 103 out of which 99 were hanging and four ligature strangulation cases. Author noticed that the ligature mark in every hanging case was obliquely placed and placed at or above the level of thyroid cartilage in $70(70.25 \%)$ cases and at the level of thyroid cartilage in 29 (29.75\%) cases, where as in all four ligature strangulation cases, the mark was transverse and below the level of thyroid cartilage. The internal appearance of underlying soft tissues of neck was pale, white and glistening in all 99 cases of hanging while in the entire four cases of ligature strangulation it showed extravasation of blood. Dribbling of saliva was present in $40(39.6 \%)$ cases of hanging but not present in any cases of ligature strangulation (Table no.1).

Table N0.1 Various External Autopsy findings:

\begin{tabular}{|l|l|l|}
\hline $\begin{array}{l}\text { External autopsy } \\
\text { findings }\end{array}$ & Hanging & $\begin{array}{l}\text { Ligature } \\
\text { Strangulation }\end{array}$ \\
\hline Dribbling of Saliva & $40(39.6 \%)$ & 0 \\
\hline $\begin{array}{l}\text { Face congestion } \\
\text { and cyanosis }\end{array}$ & 0 & $35(35.35 \%)$ \\
\hline $\begin{array}{l}\text { Blood discharge } \\
\text { from nose and mouth }\end{array}$ & $3(3.03 \%)$ & $100 \%$ \\
\hline Urinary discharge & $25(25.25 \%)$ & 0 \\
\hline $\begin{array}{l}\text { Semen on tip of } \\
\text { glans penis }\end{array}$ & $18(18.18 \%)$ & 0 \\
\hline $\begin{array}{l}\text { Fecal material } \\
\text { discharge }\end{array}$ & $13(13.13 \%)$ & $1(25 \%)$ \\
\hline
\end{tabular}

Blood discharge from mouth and nose was found in the entire four cases of ligature strangulation but only in three cases (3.03\%) of hanging (Table no.1). Congestion of face and cyanosis present in $35(35.35 \%)$ cases of hanging while it was present in the entire four cases of ligature strangulation (Table no.1). In 99 cases of hanging, hyoid bone was fractured only in 15 cases $(15.15 \%)$ which of were more than 38 years age. Out 
of 103 cases, 61cases (59.22\%) were male and 42 cases $(40.88 \%)$ were female. In hanging cases male predominated the females as number of male was 59 where as female was 40 whereas it was equal in ligature strangulation cases as male and female both were two in number (Table no.2).

Table no.2 Sex wise Distribution of cases:

\begin{tabular}{|lll|}
\hline Sex & Hanging & Ligature Strangulation \\
\hline Male & 59 & 2 \\
\hline Female & 40 & 2 \\
\hline
\end{tabular}

In total cases of fatal neck compression Age group of 21-30 years of age were predominant (Table no.3).

Table no.3 Age wise distribution of cases:

\begin{tabular}{|ll|}
\hline Age group & Number of cases \\
\hline 10-20Years & 5 \\
\hline 21-30Years & 61 \\
\hline 31-40Years & 17 \\
\hline 41-50Years & 12 \\
\hline 51-60Years & 8 \\
\hline
\end{tabular}

In two cases $(2.02 \%)$ of hanging thyroid cartilage was fractured (Table no.4), which were male. Hyoid bone and thyroid cartilage, cricoid cartilage were not fractured in any case of ligature strangulation (Table no.4).

Table no. 4 Fracture of Hyoid bone and Thyroid cartilage in internal Autopsy findings:

\begin{tabular}{|l|l|l|l|}
\hline Cases & $\begin{array}{l}\text { Fracture } \\
\text { hyoid } \\
\text { bone }\end{array}$ & $\begin{array}{l}\text { Fracture } \\
\text { thyroid } \\
\text { cartilages }\end{array}$ & $\begin{array}{l}\text { Fracture of } \\
\text { Trachea,Larynx } \\
\text { and vertebra of } \\
\text { cervical region }\end{array}$ \\
\hline Hanging & $15(15.15 \%)$ & $2(2.2 \%)$ & 0 \\
\hline $\begin{array}{l}\text { Ligature } \\
\text { Strangu- } \\
\text { lation }\end{array}$ & 0 & 0 & 0 \\
\hline
\end{tabular}

Trachea, Larynx and vertebra of cervical region were not fractured in any case of hanging and ligature strangulation. In this study, 80 cases $(80.80 \%)$ of hanging did not show any injuries around the ligature marks, while in the entire four cases of ligature strangulation, injuries were present around the ligature mark (Table no.5).
Table no.5 Injuries around the ligature mark:

\begin{tabular}{|l|l|l|}
\hline $\begin{array}{l}\text { Injuries } \\
\text { around } \\
\text { ligature } \\
\text { mark }\end{array}$ & Hanging & $\begin{array}{l}\text { Ligature } \\
\text { Strangulation }\end{array}$ \\
\hline Abrasion & $19(19.19 \%)$ & $4(100 \%)$ \\
\hline Bruises & $19(19.19 \%)$ & $4(100 \%)$ \\
\hline Rope Burn & $19(19.19 \%)$ & $4(100 \%)$ \\
\hline
\end{tabular}

\section{DISCUSSION:}

In the present study of total 103 cases of fatal neck compression by ligature, 99 cases $(96.11 \%)$ were of hanging and four cases $(3.88 \%)$ were of ligature strangulation.

Dribbling of saliva was found in 39 cases (40\%) of hanging and not found in all four cases of ligature strangulation (Table no.1) in external autopsy finding. The findings are almost consistent with those of Ashok Kumar Samanta et $\mathrm{al}^{6}$ who observed $32.31 \%$ cases with dribbling of saliva. Sarangi M.P. ${ }^{7}$ observed dribbling of saliva in 14 cases $(11 \%)$ of hanging and not found in any cases of ligature strangulation. Dribbling of saliva is surest sign of hanging happened during life. Paliwal P K. et al ${ }^{8}$ with the help of investigative and reconstructive Forensic Medicine to decodify the mystery of death by saliva found in the form of drop over the lower lip as observed in the photographs taken from the scene of crime, they opined it was ante-mortem hanging.

Blood discharge from mouth and nose was seen only in only three cases of hanging while it was present in all four cases of ligature strangulation (Table no.1), which is also consistent with observations of Sarangi M.P. ${ }^{7}$ Involuntary discharge of urine was present in 25 cases, fecal discharge present in 18 cases and semen on glans penis present in 13 cases of hanging while involuntary discharge of fecal matter was present in only one case of ligature strangulation (Table no.1). In case of hanging, incidence of fracture of hyoid bone in 15cases (15.15\%) is almost similar with study of Sarangi et al ${ }^{7}$ and Chormunge Patil et al ${ }^{9}$ but lower than study of Tripude B H. et al. ${ }^{10}$ In ligature strangulation incidence of fracture of hyoid bone was $14.28 \%$ observed by Sheikh M I. et al ${ }^{11}$ and $12.5 \%$ by Chormunge Patil et al. ${ }^{9}$ These are different from this study in which hyoid bone was not fractured in any case of ligature strangulation and the 
reason might be due to observation in very less number of ligature strangulation case.

In present study, incidence of injury to thyroid cartilage was observed in Two $(2.02 \%)$ cases, which is similar to study of Meera et al ${ }^{12}$, who observed injury to thyroid cartilage was in $2.38 \%$ cases. Fracture of cricoid cartilage, tracheal rings and cervical vertebrae were not observed in any cases of neck compression which was similar to observation of Meera et al ${ }^{12}$ and Chormunge Patil et al. ${ }^{9}$ Injuries around the ligature mark in the form of abrasion bruise and rope burns were present in $19(19.19 \%)$ cases of hanging and in all four cases $(100 \%)$ of ligature strangulation (Table no.5). The rope burns (friction burns) are due to friction of the ligature material against the skin due to slippage of the material. The above features were observed in the studies conducted by Pradeep Kumar et al. ${ }^{13}$. In 99 cases of hanging, on the basis of circumstances of death and postmortem findings the manner of death was suicidal.

While in four cases of ligature strangulation in two cases, the manner of death was homicidal and in next two cases it was accidental. Accidental strangulation is not very common, but it may occur when an article of clothing, a neck band, a cord, or a chain is tightly drawn round the neck all of a sudden, occasionally seen in male worker, who are caught by moving belt of machine. In present study, a case of accidental ligature strangulation in 55 years female was observed who was entrapped under influence of alcohol in a wooden and bamboo gate (tagaro) while entering her house. Similar case of accidental ligature strangulation was observed by Zine K U. et $\mathrm{a}^{14}$ and Punia RK, Gupta BM. ${ }^{15}$ If an autopsy surgeon become very careful and thoroughly see the external and internal autopsy findings in fatal neck compression cases specially in Hanging and ligature strangulation cases then in such dilemma it will be useful to differentiate between ligature made by hanging and ligature made by strangulation.

\section{CONCLUSION:}

In fatal neck compression cases external autopsy findings like dribbling of saliva from angle of mouth, facial pallor, urine and fecal material discharge were common finding in 99 cases of hanging where as it was variable in ligature strangulation cases. Similarly fracture of hyoid bone and thyroid cartilage was found in hanging cases with age greater than 38 years but not in any ligature strangulation cases as an internal autopsy finding. Hence, the external and internal autopsy findings are very helpful for autopsy surgeons when there is dilemma in fatal neck compression cases especially in Hanging and ligature strangulation cases. In suspicious cases final opinion can be made depending upon circumstantial evidence, crime scene investigation, external and internal postmortem findings.

\section{REFERENCES:}

1. Jaising $\mathrm{p}$ modi. Edited by Justice K Kannan, Dr KarunakaranMathiharan, Modi A Textbook of medical jurisprudence and toxicology.Lexis Nexis Publications;24 ${ }^{\text {th }}$ edition; 2013 pp 445.

2. K.S. Narayan Reddy, Dr.O.P. Murty, The essentials of Forensic medicine and Toxicology., The Healthscience Publishers, $33^{\text {rd }}$ edition; 2014 pp 338.

3. Maio VJ, Di MaioDJ.Forensic Pathology, $2^{\text {nd }}$ edition,CRC press,newyork;2001.Chapter 8 Asphyxia.

4. Nageshkumar G Rao, Textbook of Forensic Medicine $\&$ Toxicology, $2^{\text {nd }}$ edition, Jaypee brothers medical publishers (p) ltd;2010pp195.

5. Nageshkumar G Rao, Textbook of Forensic Medicine \&Toxicology, $2^{\text {nd }}$ edition, Jaypee brothers medical publishers (p) ltd;2010pp 206

6. Ashok Kumar Samanta, Soumya Rajan Nayak. Newer trends in hanging death. Journal of Indian Academy of Forensic Medicine. 2012; Vol. 34 (1) pp37-39.

7. Sarangi M. P. "Ligature mark/s" - In Forensic pathologist's perspective. Journal of Forensic Medicine and Toxicology. Jan - June 1998; Vol. 15(1) pp 99- 102

8. Paliwal P. K, Basant Lal Sirohiwal, Vijay Pal Khanagwal, Hitesh Chawla. A drop of saliva decodes the mystery of hanging body. Journal of Indian Academy of Forensic Medicine. July-Sep 2011; Vol. 33 (3) pp280-282.

9. Chormunge Patil, Mahajan S. V, Bhusari P. A. Hanging vs. strangulation a comparative study. Journal of Forensic Medicine, Science and Law. Jul-Dec 2011;Vol. 20, (2) pp 1-5

10. Tripude B H, Murkey P N, Pawar V G, Shende 
S A. Profile of Hanging Cases on Autopsy at a

Tertiary Care Hospital In Central India. Journal of Karnataka Medico-legal Society Jan-Jun 2010; Vol. 19(2) pp 3-7.

11. Sheikh M. I. and Agarwal S. S. Medico-legal implications of hyoid bone fracture- a study paper. Journal of Indian Academy of Forensic Medicine. 2001;Vol. 23(4)pp 61 - 63.

12. Th. Meera, Bipin Kumar Singh M. Pattern of neck findings in suicidal hanging. Journal of Indian Academy of Forensic medicine. Oct-Dec 2011;Vol 33( 4) pp350-352.

13. Pradeep Kumar G., Manoj Kumar Mohanty, ShanavazBaipady. "Rope Burns: A feature of Antemortem Hanging". Journal of Karnataka Medico-legal Society, 2002; Vol 11 (2): pp25-26.

14. Zine K. U., Tandle R. M., Varma N. M., Jambure M. P. Accidental Ligature Strangulation with Avulsion of Scalp. Journal Indian Academy Forensic Medicine. July-Sept 2011;Vol. 33(3)pp 267-268.

15. Punia R. K, Gupta B. M. A rare case of ligature strangulation with salivary staining. Journal Indian Academy Forensic Medicine. Vol. 31(3 ) pp 262-263. 